\title{
EFEITO DA QUALIDADE DA SOLUÇÃO DE ARLA 32 NA EFICIÊNCIA DO SCR, NAS EMISSÕES DE NOx E NO SISTEMA DE INJEÇÃO DE ARLA
}

\author{
Tadeu Cavalcante Cordeiro de Melo ${ }^{1}$, Airton Giongo ${ }^{1}$, Marcos Fernando Mendes Brito ${ }^{1}$, \\ Francisco de Assis Freitas ${ }^{1}$, Luís Carlos Pires ${ }^{1}$, Claudio Agostinho Furlan ${ }^{2}$ e José Antônio de \\ Souza Junior ${ }^{2}$ \\ ${ }^{1}$ CENPES - PETROBRAS \\ ${ }^{2}$ UMICORE
}

E-mails: tcm@petrobras.com.br, airton.giongo@petrobras.com.br, marcosfernando@petrobras.com.br, claudio.furlan@am.umicore.com, jose.souza@am.umicore.com.

\section{RESUMO}

A solução ARLA 32 contém 32,5\% de ureia de elevada pureza e 67,5\% de água desmineralizada e fornece amônia ao sistema SCR para a redução das emissões de NOx. Com o crescimento desse mercado no país surgiram alterações na sua qualidade que podem comprometer as emissões de NOx e a durabilidade do SCR. Entre exemplos de alterações de qualidade foram relatados produtos com excesso de água, uso de água potável e também o uso de ureia fertilizante ou industrial. Estas formulações, de forma geral, não atendem a especificação do ARLA 32, IN-n ${ }^{\circ} 23$ de 11 de julho de 2009 do IBAMA. As formulações preparadas para esse trabalho incluem o uso de água potável comum, ureia fertilizante e ureia industrial, que simulam algumas das alterações de qualidade do mercado. Esse artigo apresenta resultados das emissões de NOx em um motor CONAMA P7 com SCR em banco de provas de motor e o impacto no sistema de injeção de ARLA 32do uso dessas formulações. No artigo também são apresentados resultados de emissões de NOx, com o uso de um sistema de medição embarcado, em um caminhão CONAMA P7 equipado com SCR na configuração original e com o uso de dispositivo emulador ("chip"), que inibe a injeção de ARLA 32.

\section{INTRODUÇÃO}

Com a entrada em vigor da fase CONAMA P7 do PROCONVE, em 2012, exigindo novos limites de emissões para veículos pesados, em especial NOx e material particulado (MP), se tornou necessário um grande avanço na tecnologia de motores a diesel[1]. Foram definidas então duas rotas tecnológicas principais: o EGR (Exhaust Gas Recirculation) e o SCR (Selective Catalyst Reduction - catalisador redutor de NOx).

No caso da tecnologia EGR, uma parte dos gases de escapamento é redirecionada para a admissão, passando por uma válvula de controle e por um resfriador. Com isso, o gás de escape é reintroduzido na câmara de combustão de forma controlada para reduzir a quantidade de oxigênio e a temperatura da combustão, reduzindo as emissões de NOx. 
No caso da tecnologia SCR, a combustão dentro da câmara é otimizada ao máximo de forma a reduzir o consumo, atingindo temperaturas mais altas e queimando a maior parte dos compostos de carbono, o que minimiza a emissão de material particulado. Entretanto, essa alta temperatura aliada à grande disponibilidade de oxigênio também promove a formação de óxidos de nitrogênio (NOx) que ultrapassam o limite de emissão legislada.

Para sanar esse problema, é utilizado o catalisador SCR, cujo funcionamento se baseia na injeção controlada de uma solução de ureia $(32,5 \%)$ e água desmineralizada $(67,5 \%)$ chamada ARLA 32, que, em contato com a alta temperatura dos gases de escape, sofre hidrólise e se transforma em amônia, amônia essa que reage no catalisador de redução neutralizando o NOx, como ilustrado na figura 1.

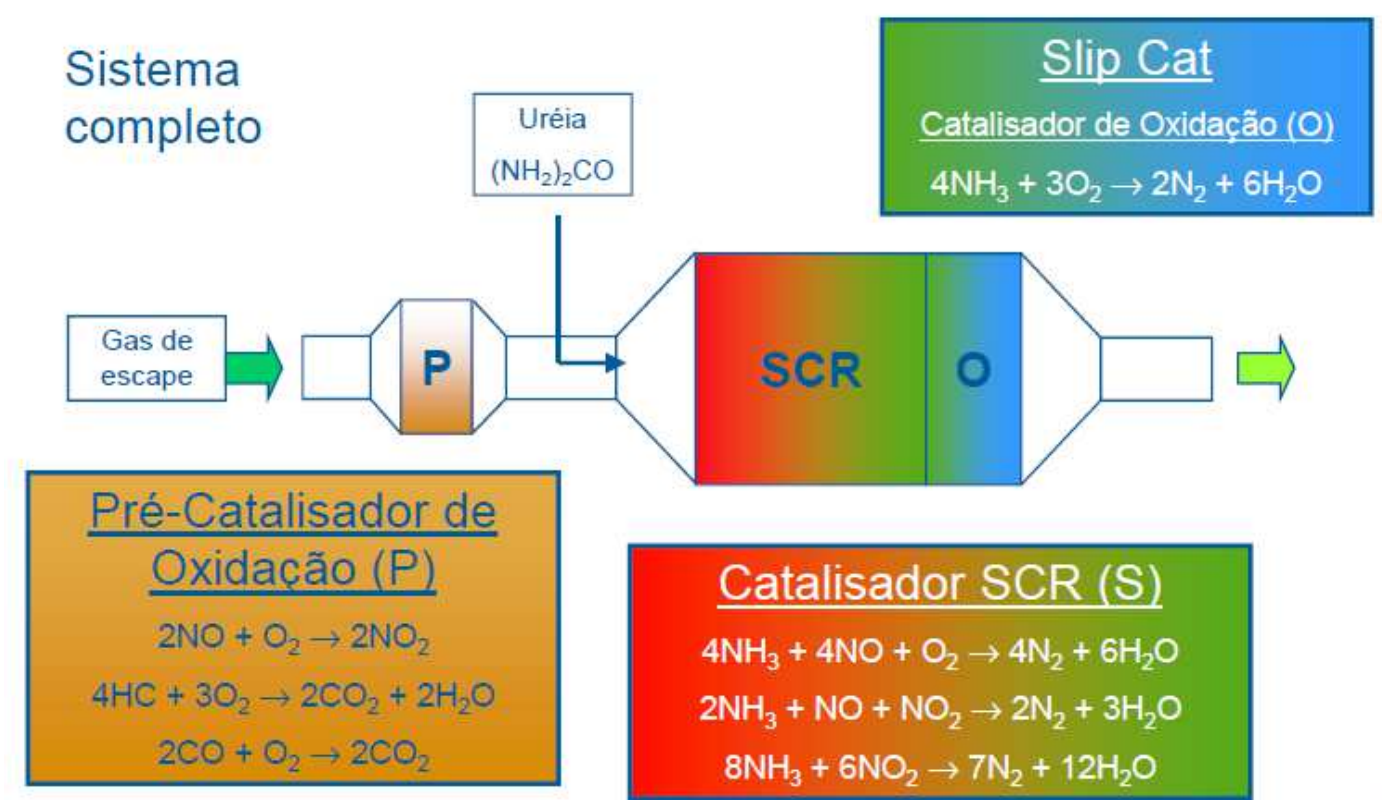

Figura 1 - Sistema SCR e principais reações químicas (fonte:Umicore)

Devido aos custos do uso do ARLA 32 no Brasil para os proprietários dos veículos, surgiram, então, práticas para reduzir ou eliminar esse consumo, especialmente nos caminhões pesados, que podem ocorrer principalmente de duas formas [2]:

a) modificação do produto ARLA 32 comercializado;

b) Inibição da injeção de ARLA 32 por dispositivo eletrônico instalado no veículo (“chip”).

Este cenário levou a PETROBRAS e a UMICORE a estudarem o impacto nas emissões de NOx do uso modificado do ARLA 32 em sistemas SCR, tanto em banco de provas de motores, como em caminhão da fase CONAMA P7.

Apesar de existirem vários trabalhos publicados sobre o sistema SCR e a solução de ureia [3,4,5], não foram encontradas muitas publicações relacionando as emissões de NOx com a qualidade da solução de ureia usada [6,7]. 


\section{PRODUÇÃ̃ DE ARLA 32}

No Brasil, o ARLA 32 é produzido a partir de correntes intermediárias do processo de produção de ureia ou da dissolução de ureia sólida contendo baixos teores de biureto.

O processo de produção de ureia pode ser dividido, de forma simplificada, em 5 (cinco) etapas: síntese, decomposição e absorção, concentração, acabamento e tratamento de efluentes (figura 2). A etapa de síntese é onde ocorre a formação da ureia a partir de suas matérias primas, amônia e dióxido de carbono, que passa pela formação de um intermediário químico, chamado de carbamato de amônio.

Na etapa de decomposição, a ureia é purificada através da decomposição do carbamato de amônio não convertido em ureia, que recicla para a seção de síntese. A ureia efluente da seção de decomposição, na verdade uma solução de ureia tendo concentração entre 60 e $80 \%$, segue para a etapa de concentração onde sua água é evaporada. Em seguida a solução chega à seção de acabamento, onde será dada a forma final da ureia em perolas ou grânulos.

Todos os efluentes das etapas anteriores seguem para a etapa de tratamento de efluentes, na qual os compostos são hidrolisados em amônia e dióxido de carbono que retornam à seção de síntese. O efluente do tratamento de efluentes de uma planta de ureia é água contendo $1 \mathrm{ppm}$ de ureia e 3 ppm de amônia.

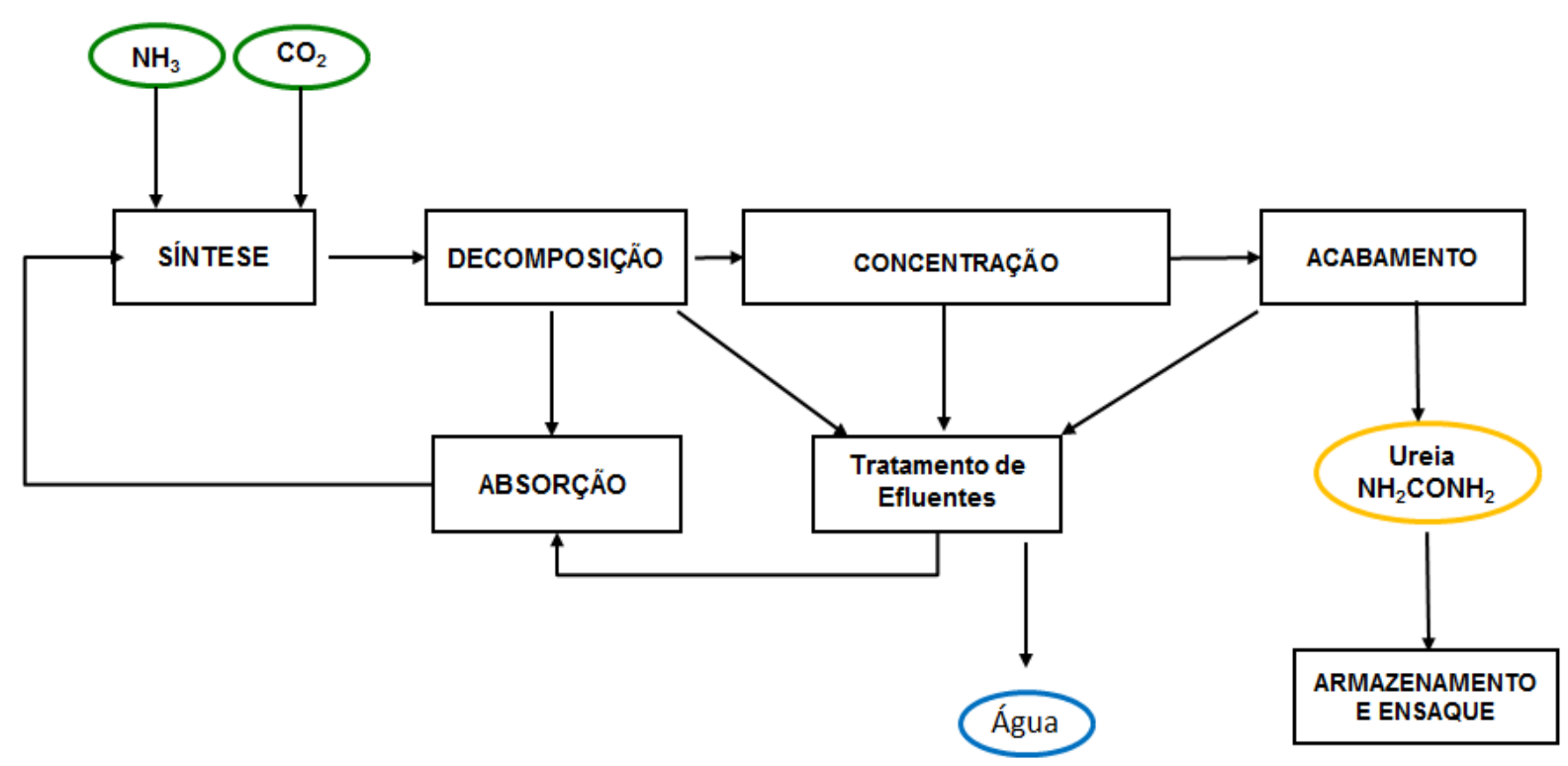

Figura 2 - Diagrama de Blocos do processo de Ureia

O biureto é um contaminante do processo de produção de ureia, sendo limitante para a produção do ARLA 32, produto no qual o teor máximo aceito é de $0,3 \%$ [8]. O biureto é gerado, principalmente, nas etapas de processo em que o teor de amônia livre é baixo e a temperatura encontra-se elevada, por exemplo, na seção de concentração e na de acabamento. É formado pela reação de duas moléculas de ureia com a perda de uma molécula de amônia, conforme equação 1 . 
Portanto, o processo mais comum de produção do ARLA 32 é realizar o desvio de parte da corrente efluente da etapa de decomposição e misturar água desmineralizada. No controle das vazões da solução de ureia e de água desmineralizada, para os ajustes da concentração final desejada para o ARLA 32, são utilizados densímetros e refratômetros on-line.

O uso de ureia fertilizante e pecuária no preparo do ARLA 32 não é recomendado, pois nestes produtos é encontrado formaldeído em concentração elevada, que é adicionado à ureia para melhorar suas qualidades físicas. Também há a presença de biureto em teores superiores a $1 \%$, o que inviabiliza seu uso na formulação do ARLA 32 por conta da legislação. O uso da ureia industrial, embora seja isenta de formaldeído, também não é recomendado para o preparo do ARLA 32, uma vez que o teor de biureto em suas pérolas pode superar 0,95\%, equivalendo a valor maior do que $0,3 \%$ de biureto especificado para a formulação final do ARLA 32 [8].

\section{FORMULAÇÕES E ANÁLISES DE ARLA 32}

Para a realização do teste de bancada, foi fornecido um ARLA 32 comercial especificado pela BR Distribuidora (Flua), que foi usado como referência (ARLA_ref) nos ensaios de emissões de NOx e, além disso, foram produzidas quatro diferentes formulações do ARLA 32, simulando adulterações:

a) adição de $10 \%$ de água comum ao ARLA 32 de referência (ARLA_ref) - ARLA_AGC ;

b) ureia sólida fertilizante em 67,5\% de água desmineralizada (AGD) - FERT_AGD;

c) ureia sólida fertilizante em $67,5 \%$ de água potável comum (AGC) - FERT_AGC;

d) ureia sólida industrial em 67,5\% de água desmineralizada (AGD) - IND_AGD.

As amostras de ARLA 32 formuladas estão identificadas na tabela 1.

Tabela 1: Codificação das amostras de ARLA 32utilizadas no trabalho

\begin{tabular}{|ccc|}
\hline Amostra & Pureza da Água & Base de ureia \\
ARLA_ref & - & ARLA 32 Flua Petrobras \\
ARLA_AGC & Potável comum & ARLA 32 Flua Petrobras \\
FERT_AGD & Desmineralizada & Fertilizante \\
FERT_AGC & Potável comum & Fertilizante \\
IND_AGD & Desmineralizada & Industrial \\
\hline
\end{tabular}

Todas as amostras foram analisadas nos laboratórios da Petrobras para caracterização e comparação com a especificação da NBR ISO 22241-1 [8,9]. A Tabela 2 mostra um resumo das análises de todas as formulações. A última coluna (ESPEC.) indica os limites de especificação do ARLA 32 [8]. Valores sinalizados com “**” não atendem ao especificado. 
Tabela 2: Resumo das análises das formulações de ARLA 32 testadas

\begin{tabular}{|c|c|c|c|c|c|c|}
\hline Propriedade & ARLA_ref & ARLA_AGC & FERT_AGD & FERT_AGC & IND_AGD & ESPEC. \\
\hline $\begin{array}{l}\text { Índice de } \\
\left.\text { refração (a } 20^{\circ} \mathrm{C}\right)\end{array}$ & 1,3831 & 1,3798 & 1,3831 & 1,3824 & 1,3827 & $\begin{array}{c}1,3814 \mathrm{a} \\
1,3843\end{array}$ \\
\hline Ureia $(\%)$ & 32,4 & 30,4 & 32,4 & 32,1 & 32,1 & $\begin{array}{c}31,8 \mathrm{a} \\
33,2\end{array}$ \\
\hline $\begin{array}{l}\text { Massa } \\
\text { específica }\left(\mathrm{kg} / \mathrm{m}^{3}\right)\end{array}$ & $1.090,3$ & $1.084,3$ & $1.090,2$ & $1.089,2$ & $1.089,5$ & $\begin{array}{l}1.087,0 \mathrm{a} \\
1.093,0\end{array}$ \\
\hline amônia (\%) & $<0,1$ & $<0,10$ & $<0,1$ & $<0,1$ & $<0,1$ & $<0,2$ \\
\hline Biureto $(\%)$ & 0,3 & 0,2 & 0,3 & 0,3 & $0,4 * *$ & Max. 0,3 \\
\hline Aldeído (mg/kg) & 1,4 & 0,7 & $9 * *$ & $6,7 * *$ & 0,6 & 5 \\
\hline Insolúveis (mg/kg) & 4,6 & 7,3 & 4,8 & 5,1 & $<1,0$ & $<20$ \\
\hline Fosfato $(\mathrm{mg} / \mathrm{kg})$ & $<0,10$ & $<0,10$ & $<0,10$ & 0,14 & $<0,10$ & $<0,5$ \\
\hline Cálcio (mg/kg) & $<0,02$ & $1,19 * *$ & $<0,02$ & $4,26 * *$ & $<0,02$ & $<0,5$ \\
\hline Ferro $(\mathrm{mg} / \mathrm{kg})$ & 0,02 & $<0,01$ & 0,05 & 0,34 & 0,04 & $<0,5$ \\
\hline Cobre $(\mathrm{mg} / \mathrm{kg})$ & $<0,01$ & $<0,01$ & $<0,01$ & $<0,01$ & $<0,01$ & $<0,2$ \\
\hline Zinco $(\mathrm{mg} / \mathrm{kg})$ & 0,06 & 0,02 & $<0,01$ & 0,08 & 0,03 & $<0,2$ \\
\hline Cromo (mg/kg) & 0,02 & 0,04 & 0,03 & 0,02 & 0,10 & $<0,2$ \\
\hline Níquel (mg/kg) & $<0,01$ & 0,03 & 0,02 & $<0,01$ & 0,07 & $<0,2$ \\
\hline Magnésio (mg/kg) & 0,03 & 0,02 & 0,04 & $0,88 * *$ & 0,04 & $<0,5$ \\
\hline Sódio (mg/kg) & 0,07 & $3,40 * *$ & 0,40 & $6,50 * *$ & 0,44 & $<0,5$ \\
\hline Potássio (mg/kg) & $<0,03$ & 0,03 & $<0,03$ & $1,28 * *$ & $<0,03$ & $<0,5$ \\
\hline Alumínio (mg/kg) & 0,07 & 0,04 & 0,05 & 0,07 & $<0,01$ & $<0,5$ \\
\hline
\end{tabular}

As análises reportadas na tabela 1 demonstram que a amostra de referência, ARLA_ref (Flua), fornecida pela BR Distribuidora, está totalmente enquadrada na especificação NBR ISO 22241-1 [8]. A amostra IND_AGD, feita a partir de ureia industrial, apresentou o teor de biureto mais elevado de todas as amostras $(0,4 \%)$ e não atendeu a especificação. $O$ atendimento ao limite máximo do teor de biureto é importante, pois segundo LEAL [10] existe uma relação entre teores acima de $0,3 \%$ de biureto e a formação de depósitos no injetor de ureia.

As amostras ARLA_AGC e FERT_AGC, por utilizarem água potável comum em sua formulação, apresentaram teores muito elevados de sódio e cálcio. Cabe ressaltar que, no caso da amostra FERT_AGC, também foram encontrados valores acima da especificação para o magnésio e potássio. As amostras FERT_AGD e FERT_AGC feitas a partir de ureia fertilizante não atenderam ao limite de teor de aldeídos. 


\section{METODOLOGIA}

\subsection{Ensaios de emissões em motores}

Foram conduzidos ensaios de emissões em ciclos de banco de provas de motores de acordo com a norma NBR 15634 [11], de dois tipos diferentes:

- Transiente (ETC - European Transient Cycle) simulando variações contínuas de carga e rotação;

- Estacionário (ESC - European Stationary Cycle), com 13 pontos de operação.

Foram realizadas três repetições dos ensaios com a solução ARLA 32de referência (Flua) e pelo menos duas repetições com cada formulação testada.

Ao final dos ensaios, para cada amostra, foi feita uma análise do injetor de ureia para verificação quanto à formação de depósitos. Depois, o sistema de injeção de ureia era drenado e o injetor limpo. Nesse momento, a nova amostra era abastecida no reservatório e o motor era condicionado por alguns minutos na rotação $\mathrm{B}$ do ciclo ESC, com $30 \%$ do torque máximo.

Foi utilizado um motor da fase CONAMA P7, com capacidade volumétrica de 6,7 litros e potência de $280 \mathrm{cv}$, equipado com catalisador (SCR). O combustível utilizado em todos os ensaios foi um óleo diesel comercial S10 de uma única batelada, comprado da BR Distribuidora que atende a especificação da ANP.

O banco de provas de motor utilizado foi o da empresa UMICORE, que usa um sistema de automação apropriado para ensaios de desempenho de sistemas de póstratamento e dinamômetro assíncrono do fabricante Kratzer, de 620 kW / 3300 Nm. A análise de NOx foi feita com uma bancada de emissões da AVL, modelo i60. O banco de provas contava com um sistema de injeção de solução de ureia, que permitia um controle da quantidade injetada e uma purga eficiente no momento da troca entre amostras de ARLA 32. Na Figura 2 podem ser vistas fotos do banco de provas com detalhes da localização do injetor de ARLA 32 no escapamento.
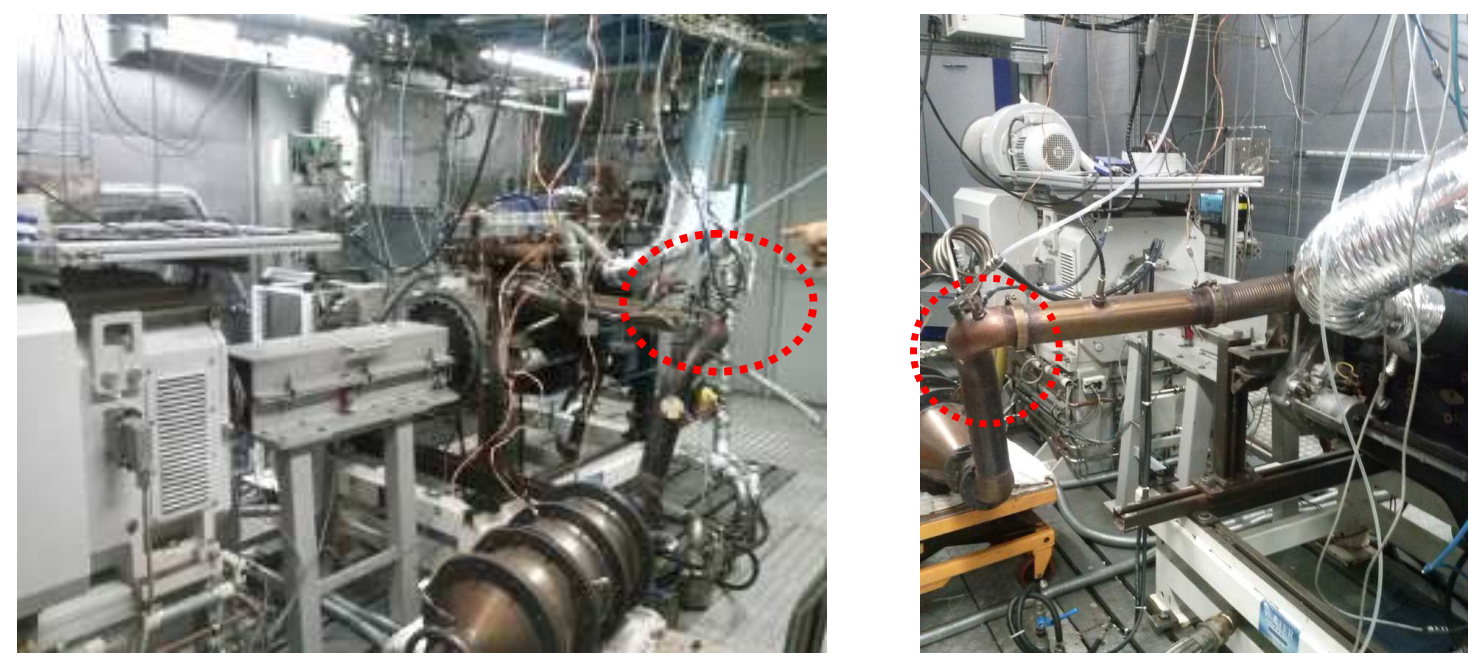

Figura 2: Banco de Provas - detalhes de localização do injetor de ARLA. 
O banco de provas utilizado conta com um moderno sistema de controle, capaz de medir, com precisão, o volume de solução de ureia injetada no sistema, bem como controlar esse volume.

Um catalisador de redução de NOx tem uma operação complexa, necessitando atenção aos parâmetros de funcionamento, principalmente temperatura, rotação e carga do motor, para evitar tanto uma injeção insuficiente de solução quanto uma injeção demasiada. No primeiro caso, a falta de reagente redutor causaria ineficiência na conversão, que resultaria em aumento da emissão de NOx, enquanto que, no segundo caso, o excesso de solução levaria a uma emissão de amônia não reagida na saída do escape. Como a injeção de ARLA 32 só pode ocorrer a partir da temperatura em que o catalisador começa a se tornar eficiente, o que acontece acima de $200^{\circ} \mathrm{C}$, durante a fase de aquecimento do motor, não há injeção de ureia. Quando o motor se encontra aquecido, o sistema de injeção passa a operar e a solução de ureia é injetada numa proporção de ureia equivalente ao necessário para converter cerca de $80 \%$ do NOx emitido pela combustão, o que depende das condições de rotação e carga do motor. Essa injeção de $80 \%$ em relação à quantidade estequiométrica é designada pelo fator alfa (@), que foi ajustado para 0,8 para todos os testes realizados.

Durante os ensaios de emissões foram feitas duas medições de NOx no escape, de forma simultânea:

- uma antes do sistema de pós-tratamento (SCR) ou medição de NOx bruto;

- uma após o sistema de pós-tratamento (SCR) ou NOx emitido no escapamento.

Em média, durante os ensaios ETC e ESC, o motor utilizado emitiu cerca de 7,6 $\mathrm{g} / \mathrm{kWh}$ de NOx (bruto) que, após o sistema de pós-tratamento, era reduzido para cerca de 1,5 g/kWh de NOx (escapamento) com o uso do ARLA 32 da amostra de FLUA.

O cálculo do rendimento da conversão de NOx foi feito pela divisão do NOx convertido pelo NOx gerado pelo motor, equação (2), sendo o NOx convertido calculado pela diferença entre o NOx gerado pelo motor e o emitido pelo escapamento, equação (3).

$$
\begin{aligned}
& \operatorname{NOx}_{(\text {convertido) }} / \mathrm{NOx}_{(\text {gerado) }} * 100 \%=\text { rendimento } \\
& \operatorname{NOx}_{(\text {gerado) }}-\operatorname{NOx}_{(\text {emitido) }}=\operatorname{NOx}_{(\text {convertido })}
\end{aligned}
$$

O NOx convertido se refere ao que foi reagido no SCR. As equações (4) e (5) mostram como a solução aquosa de ureia, ao entrar em contato com os gases quentes do escapamento, se transforma em amônia (NH3), processo de termo hidrólise.

$$
\begin{aligned}
& \begin{array}{l}
\text { Ureia(aquosa) } \rightarrow \text { Ureia(fundida) }+ \text { Água(vapor) } \rightarrow \text { Amônia(vapor) } \\
\text { Carbônico(gás) }
\end{array} \\
& \begin{array}{l}
\text { NH2-CO-NH2 (aquosa) } \rightarrow \text { NH2-CO-NH2(fundida) }+\mathrm{H} 2 \mathrm{O} \text { (vapor) } \rightarrow \text { Gás } \\
\text { CO2(gás) }
\end{array}
\end{aligned}
$$


Em seguida, a amônia se mistura ao NOx do escapamento e entra no catalisador, onde ocorrem as reações demonstradas nas equações (6 e 7), consumindo a amônia, o NOx e o oxigênio, e resultando em $\mathrm{N} 2$ e $\mathrm{H} 2 \mathrm{O}$ na saída do escapamento, juntamente com o NOx não reagido (emitido).

$$
\begin{array}{cc}
\text { Amônia(gás) + NOx(gás) + Oxigênio(gás) } & \rightarrow \text { Nitrogênio(gás) + Água(vapor) } \\
\text { NH3(gás) + NOx(gás) + O2(gás) } & \rightarrow \text { N2(gás) + H2O(vapor) }
\end{array}
$$

A razão para o sistema SCR ser ajustado para reagir apenas $80 \%$ do NOx é que, ao se buscar taxas de conversão maiores, seria necessário aumentar a disponibilidade de amônia na entrada do catalisador. Com isso, parte dessa amônia poderia passar sem reagir no sistema, resultando em sua saída pelo escapamento, o que é indesejável.

\subsection{Ensaios de emissões em caminhão}

Para a medição das emissões em pista de um caminhão CONAMA P7, ano 2014, com SCR, foi utilizado o equipamento de medição de emissões "on-board" chamado PEMS (Portable Emission Measurement System) fornecido pela empresa AVL, modelo M.O.V.E. e adquirido pelo CENPES (Centro de Pesquisas e Desenvolvimento da Petrobras). Ele é capaz de fazer leituras em tempo real (modo contínuo) de diversos poluentes, com o uso de dois módulos principais: sendo um de medição de gases (CO, NOx, HC, O2 e CO2) e outro de material particulado (MP). Juntamente com as medições de poluentes, é feita também a medição do fluxo total do escapamento, o que possibilita o cálculo da massa de cada poluente medido em gramas.

Este mesmo equipamento também possui um sensor de GPS, capaz de medir e registrar a velocidade do veículo em cada momento, bem como o deslocamento total ou por períodos de interesse, além de uma conexão OBD (On Board Diagnosis) capaz de ler diversos parâmetros do veículo que estiver sendo testado, desde que seja seguido o protocolo de comunicação do equipamento. Além disso, é possível utilizar outras entradas com sensores diversos, como temperatura ambiente, umidade, temperatura em pontos específicos do veículo, entre outros. Estas funcionalidades combinadas permitem expressar os valores medidos das emissões em concentração (ppm) ou em massa (gramas) por quilômetro $(\mathrm{g} / \mathrm{km})$. Para o caso de veículos compatíveis com o sistema OBD, as emissões também poderão ser expressas em massa por potência $(\mathrm{g} / \mathrm{kWh})$. Nesse estudo, entretanto, devido à falta de informações do sistema de injeção eletrônica do veículo, não foi possível fazer uso da interface de OBD do medidor de emissões.

O equipamento de medição de emissões utilizado possui: - medidor de fluxo de escape;- Sensor de temperatura e umidade externa;- módulo de analisadores GAS PEMS para medição de NO, NO2, $\mathrm{CO} 2$ e O2;- GPS; - Computador de aquisição de dados, etc.

A operação do equipamento PEMS é feita através de um computador portátil comum, que pode ser levado dentro da cabine do veículo e conectado ao equipamento de medição por cabo de rede. Pelo computador é possível iniciar ou parar a medição, 
fazer a leitura em tempo real dos parâmetros medidos e acompanhar o status do equipamento e das baterias. Para se aumentar a autonomia de funcionamento do equipamento PEMS nos testes de rua, foram instaladas seis baterias adicionais, cada uma com capacidade de $100 \mathrm{Ah}$, o que aumentou a autonomia prevista do equipamento para aproximadamente seis horas.

O CENPES recebeu autorização do IBAMA, através do coordenador do PROCONVE (Programa de Controle da Poluição do Ar por Veículos Automotores) para testar em vias públicas um dispositivo emulador de injeção de ARLA 32 ("chip"). Esse emulador tem a função de inibir a injeção de ARLA 32e também de "enganar" a central eletrônica do veículo, de forma que não apareçam erros e o veículo funcione

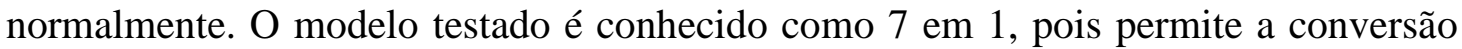
de diversos modelos de caminhão de até 7 diferentes fabricantes, incluindo o modelo de caminhão testado. Uma foto da instalação do "chip" emulador na caixa de fusível do caminhão é apresentada na figura 3 .

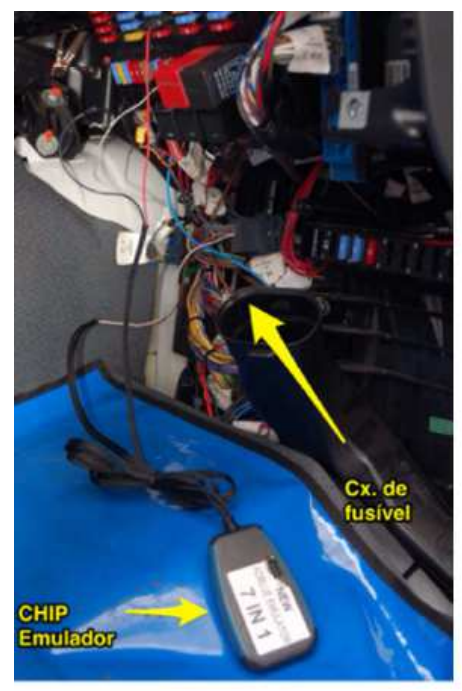

Figura 3: Detalhe da ligação do "chip" na caixa de fusível do caminhão

O "chip" foi instalado pelo CENPES com base nos arquivos de ajuda disponíveis no CD de instalação e foi ligado em paralelo com alguns sinais do módulo de injeção de ARLA 32. Ao girar a chave de ignição, o dispositivo "aprende" os sinais enviados pelo módulo do ARLA 32 para a central eletrônica do veículo. Depois deve ser retirado o fusível do módulo de ARLA 32 e o veículo já está pronto para uso na configuração sem injeção de ARLA 32.

O equipamento PEMS (“on-board”) montado no caminhão é mostrado na figura 4. 


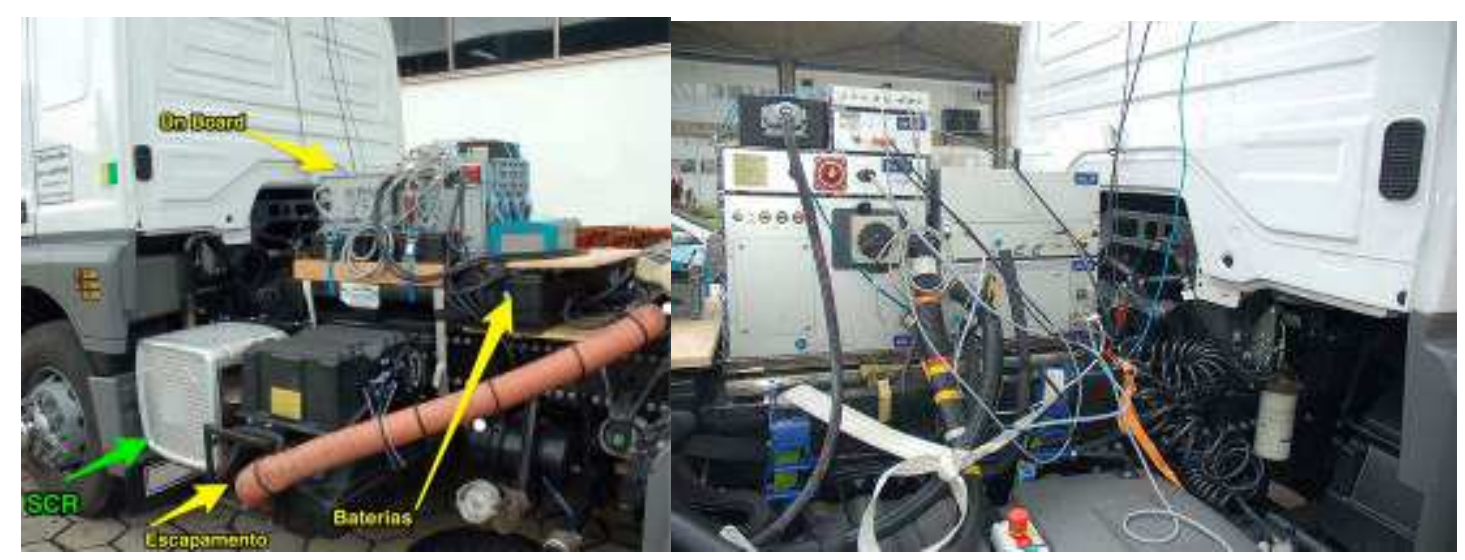

Figura 4: Equipamento PEMS instalado no caminhão.

Para reduzir a variabilidade dos dados foi definido que os testes consistiriam em rodar com o caminhão em velocidade constante de cerca de $80 \mathrm{~km} / \mathrm{h}$ em piloto automático num trecho de via pública. Primeiramente seria feita uma medição de NOx sem o uso de chip emulador de ARLA 32, ou seja, com o sistema de controle de emissões operando normalmente e, em seguida, o veículo percorreria o mesmo trecho porém com o chip inibidor do sistema de injeção de ARLA 32 instalado.

Nas medições do caminhão foram feitas as leituras de concentração de NOx (ppm), vazão mássica do escapamento, além de velocidade e distância percorrida pelo veículo, entre outros parâmetros. Isso permitiu o cálculo da emissão de NOx em g/km.

\section{RESULTADOS DOS ENSAIOS}

4.1. Resultados de emissões de NOx em banco de provas

As emissões de NOx foram medidas simultaneamente em dois pontos. O primeiro logo após a saída do motor, antes do ponto de injeção de ARLA 32, medição descrita na tabela 3 como "NOx Eng" e o segundo, logo após o SCR, identificado na tabela 3 como "NOx Escap", valor controlado pela legislação.

O rendimento de conversão do sistema SCR (REND) foi calculado como a razão entre a diferença da quantidade de NOx obtida antes e após o SCR (NOx Eng - NOx Escap) dividido pelo valor do NOx antes do SCR (NOx Eng).

A metodologia estatística de Análise de Variância (ANOVA) e a técnica de Fisher LSD foram utilizadas para avaliar a presença, ou não, de diferenças estatisticamente significativas entre as médias dos resultados de NOx das diferentes formulações. Foi usado um intervalo de confiança superior a $95 \%$ e as médias de NOx foram comparadas pelo Método da Menor Diferença Significativa (Fisher LSD) usando o valor médio do ensaio da amostra ARLA_ref como referência.

As médias dos resultados dos ensaios de emissões de NOx das diferentes amostras de ARLA 32 estão apresentadas na tabela 3, para os ciclos ETC e ESC, juntamente com os valores de rendimento de conversão do SCR (REND). Também são apresentados os 
valores de diferença significativa percentual $(\Delta)$ calculada comparando os valores de emissões de NOx das diferentes amostras (NOx Escap) em relação ao valor da referência (ARLA_ref). A sequência das formulações na tabela 3 corresponde à ordem cronológica em que foram realizados os ensaios de emissões.

Tabela 3 - Resultados de emissões de NOx (NOx Eng e NOx Escap), rendimento de SCR e diferenças percentuais em relação ao ARLA 32 de referência $(\Delta)$.

\begin{tabular}{|c|c|c|c|c|c|c|c|c|}
\hline \multirow[b]{2}{*}{ Formulação } & \multicolumn{4}{|c|}{ ETC } & \multicolumn{4}{|c|}{ ESC } \\
\hline & $\begin{array}{l}\text { NOx } \\
\text { Eng } \\
\text { [g/kWh] }\end{array}$ & $\begin{array}{l}\text { NOx } \\
\text { Escap } \\
\text { [g/kWh] }\end{array}$ & $\begin{array}{l}\text { REND } \\
{[\%]}\end{array}$ & $\begin{array}{l}\Delta \\
{[\%]}\end{array}$ & $\begin{array}{l}\text { NOx } \\
\text { Eng } \\
{[\mathrm{g} / \mathrm{kWh}]}\end{array}$ & $\begin{array}{l}\text { NOx } \\
\text { Escap } \\
\text { [g/kWh] }\end{array}$ & $\begin{array}{l}\text { REND } \\
{[\%]}\end{array}$ & $\begin{array}{l}\Delta \\
{[\%]}\end{array}$ \\
\hline ARLA_ref & 7,67 & 1,52 & 80,2 & REF. & 7,95 & 1,54 & 80,7 & REF. \\
\hline FERT_AGD & 7,59 & 1,60 & 78,9 & 5,5 & 7,86 & 1,70 & 78,4 & 10,3 \\
\hline ARLA_AGC & 7,64 & 1,86 & 75,7 & 22,3 & 7,83 & 2,03 & 74,1 & 32,1 \\
\hline FERT_AGC & 7,62 & 1,60 & 79,1 & 5,2 & 7,81 & 1,72 & 78,0 & 11,6 \\
\hline IND_AGD & 7,63 & 1,64 & 78,6 & 7,8 & 7,88 & 1,74 & 77,9 & 13,2 \\
\hline
\end{tabular}

Pode-se verificar (tabela 3) que o SCR operou com eficiência de aproximadamente $80 \%$ de conversão do NOx. Também pode ser visto que todas as formulações testadas aumentaram a emissão de NOx (NOx Escap) de 5 a 32\%, em relação ao ARLA 32de referência (ARLA_ref) dependendo do ciclo e da formulação de ARLA 32.

A amostra ARLA_AGC foi a que apresentou o maior valor de emissões de NOx no escapamento (NOx Escap = 2,03 g/kWh no ciclo ESC) e ficou no limite de 2,0 $\mathrm{g} / \mathrm{kWh}$, exigido pelo PROCONVE para a fase CONAMA P7, sem considerar o acréscimo de emissões devido a aplicação do fator de deterioração de emissões do motor. Isso ocorreu pela adição de $10 \%$ de água nessa amostra, reduzindo a quantidade de ureia disponível para a transformação em amônia e posterior redução do NOx. O aumento de NOx em relação ao ARLA 32 de referência chegou a 32\% com o uso dessa solução no ciclo ESC. As outras duas amostras que não atenderam a especificação do ARLA 32[2], FERT_AGC e IND_AGD apresentaram aumento de emissões de até $8 \%$ para o ciclo ESC e até $13 \%$ para o ciclo ESC.

Com relação à emissão bruta de NOx do motor (NOx Eng), pode ser verificado, na tabela 3, que o valor varia de 7,6 a 7,98 g/kWh dependendo do ciclo. Com o uso de um "chip", que iniba a injeção de ARLA 32, a emissão de NOx no escapamento será muito próxima da emissão bruta do motor e, portanto, muito acima do valor do limite de 2,0 g/km estabelecido pelo CONAMA. Caso isso aconteça, o valor de emissão do motor retorna ao patamar de um motor da fase CONAMA P4 ou CONAMA P3.

Para verificar a perda de rendimento médio de conversão (REND) pelo uso da formulação com adição de $10 \%$ de água comum (REND_ARLA_AGC) em comparação à referência (REND_ARLA_ref) em diferentes fases do ciclo ESC, foi elaborado o gráfico da figura 5. O gráfico também apresenta os valores médios da temperatura do SCR com o uso do ARLA de referência (TEMP SCR ARLA_ref). 


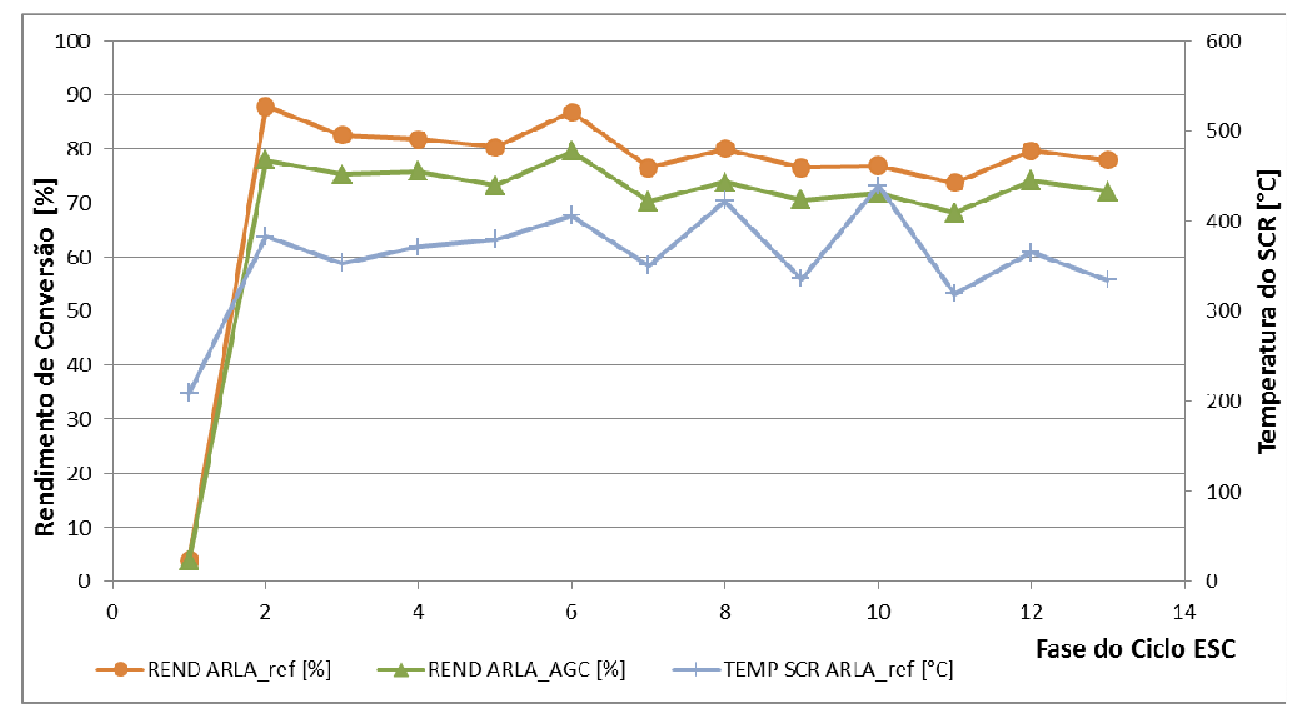

Figura 5- Rendimento, temperatura do SCR (ARLA_ref) e fase do ciclo ESC.

$\mathrm{Na}$ figura 5, pode-se verificar que os valores médios de rendimento do SCR nas diferentes fases do ciclo ESC seguem a mesma tendência, tanto para a referência (ARLA_ref), como para a formulação com adição de $10 \%$ de água comum (ARLA_AGC). Também pode ser visto que os gráficos de rendimento do SCR seguiram a tendência do gráfico da temperatura do SCR (TEMP SCR ARLA_ref).

Na tabela 4 são apresentados os valores numéricos dos gráficos da figura 5, bem como a condição operacional (torque e rotação) de cada ponto do ciclo. Também é feito um cálculo da perda de rendimento do $\operatorname{SCR}(\triangle$ REND) com o uso da formulação ARLA_AGC em relação ao ARLA 32 de referência (ARLA_ref)

Tabela 4. Valores de rendimento do SCR em diferentes pontos do ciclo ESC

\begin{tabular}{|l|l|l|l|l|l|l|l|}
\hline $\begin{array}{l}\text { Rotação } \\
{[\mathrm{rpm}]}\end{array}$ & $\begin{array}{l}\text { Torque } \\
{[\text { N.m] }}\end{array}$ & $\begin{array}{l}\text { REND } \\
\text { ARLA_ } \\
\text { ref [\%] }\end{array}$ & $\begin{array}{l}\text { REND } \\
\text { ARLA_ } \\
\text { AGC }[\%]\end{array}$ & $\begin{array}{l}\Delta \\
\text { REND } \\
{[\%]}\end{array}$ & $\begin{array}{l}\text { Temp SCR } \\
\text { ARLA_ref } \\
{\left[{ }^{\circ} \mathrm{C}\right]}\end{array}$ & $\begin{array}{l}\text { Temp SCR } \\
\text { ARLA_AGC } \\
{\left[{ }^{\circ} \mathrm{C}\right]}\end{array}$ \\
\hline 1 & 750 & 0,2 & $4 \%$ & $4 \%$ & $0 \%$ & 208 & 216 \\
\hline 2 & 1520 & 950 & $88 \%$ & $78 \%$ & $11 \%$ & 383 & 385 \\
\hline 3 & 1878 & 456 & $83 \%$ & $75 \%$ & $10 \%$ & 353 & 354 \\
\hline 4 & 1878 & 684 & $82 \%$ & $76 \%$ & $7 \%$ & 371 & 372 \\
\hline 5 & 1520 & 462 & $80 \%$ & $73 \%$ & $9 \%$ & 379 & 380 \\
\hline 6 & 1520 & 693 & $87 \%$ & $80 \%$ & $8 \%$ & 406 & 406 \\
\hline 7 & 1520 & 230 & $77 \%$ & $70 \%$ & $9 \%$ & 351 & 351 \\
\hline 8 & 1878 & 935 & $80 \%$ & $74 \%$ & $8 \%$ & 422 & 422 \\
\hline 9 & 1878 & 228 & $77 \%$ & $71 \%$ & $8 \%$ & 337 & 336 \\
\hline 10 & 2240 & 832 & $77 \%$ & $72 \%$ & $6 \%$ & 439 & 441 \\
\hline 11 & 2240 & 204 & $74 \%$ & $68 \%$ & $8 \%$ & 319 & 319 \\
\hline 12 & 2240 & 612 & $80 \%$ & $74 \%$ & $8 \%$ & 365 & 365 \\
\hline 13 & 2240 & 408 & $78 \%$ & $72 \%$ & $8 \%$ & 334 & 335 \\
\hline
\end{tabular}




\subsection{RESULTADOS DE INSPEÇÃO NO SISTEMA DE INJEÇÃO DE ARLA 32}

Os testes de emissões em banco de provas, compreendendo as repetições dos ciclos ETC e ESC, totalizaram para cada amostra cerca de 3 a 4 horas de funcionamento do motor. Mesmo com pouco tempo de funcionamento do motor, duas formulações, FERT_AGC (ureia fertilizante preparada com água comum) e IND_AGD (ureia industrial preparada com água desmineralizada), apresentaram depósitos elevados no sistema de injeção de ARLA 32.

No caso da amostra FERT_AGC, o depósito aderiu ao flange de aço inox que fica montado entre o injetor e a sede, no escape. O aspecto é cinza escuro e sem porosidade aparente, sólido, seco e frágil. A formação mostrou tendência a se depositar na parte interna da passagem do jato de ARLA, como pode ser visto na Figura 6, o que potencialmente pode piorar a qualidade da dispersão e até mesmo bloquear a injeção de ARLA 32. Esses depósitos foram causados pela presença de cálcio e outros minerais da água comum nessa formulação.
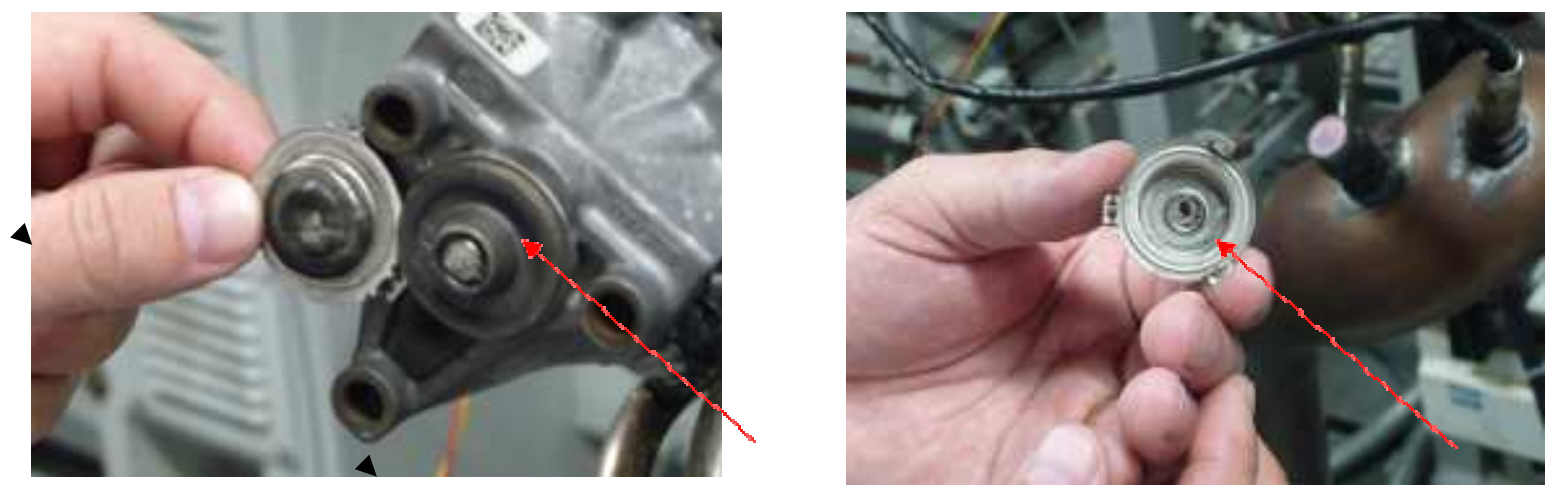

Figura 6: Presença de depósitos após os ensaios com a formulação FERT_AGC

No caso da amostra IND_AGD (figura 7), o depósito ficou aderido, principalmente, às bordas do furo da sede, também de aço inox, que fica soldada ao escapamento. Diferente do caso da amostra FERT_AGC, não houve adesão ao flange do injetor embora tenha se formado junto à face deste. O material é frágil, a coloração é negra e a superfície é porosa. O padrão de deposição foi afastado do ponto do jato de ARLA 32, com pouca tendência para o seu bloqueio.
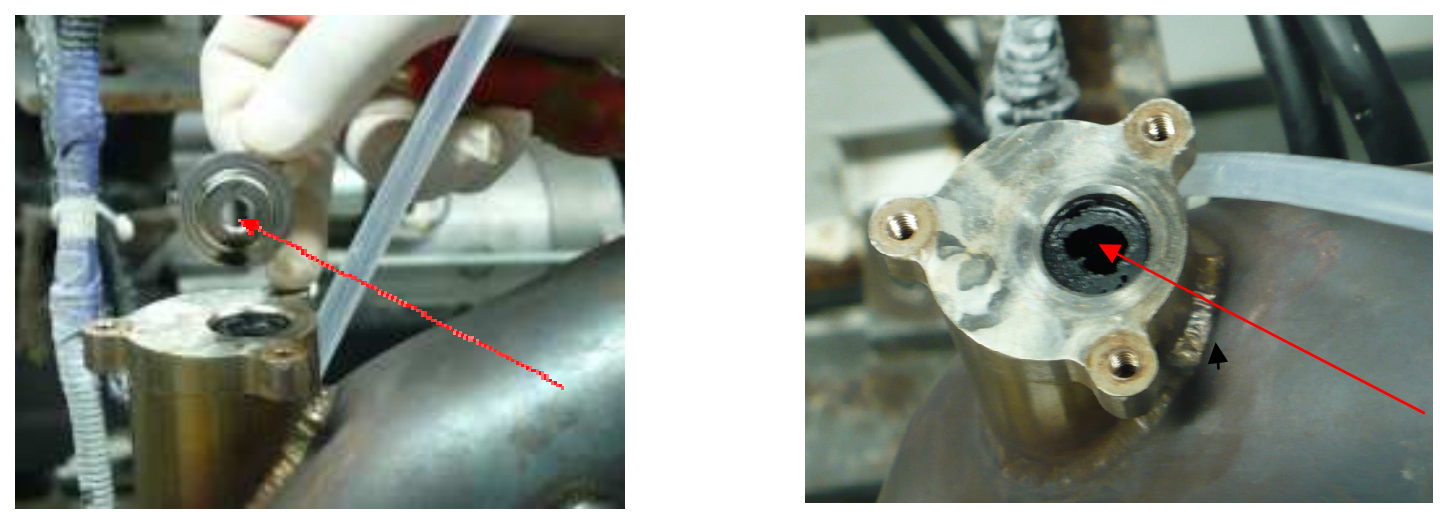

Figura 7: Presença de depósitos após os ensaios com a formulação IND_AGD

O uso prolongado dessas formulações inadequadas pode prejudicar o sistema de injeção de ARLA 32, bem como pode danificar o catalisador SCR do veículo. 


\subsection{RESULTADOS DE EMISSÕES DE NOX NO CAMINHÃO}

Com o equipamento de medição das emissões "on-board" instalado, o caminhão foi para a rua para a realização dos ensaios de medição de NOx com e sem ARLA 32. Devido ao trânsito e às condições de inclinação das vias, foi escolhido um trecho plano de uma rodovia no Rio de Janeiro para as medições comparativas. O teste foi conduzido em modo de condução do veículo com o uso do piloto automático em pista quase plana, onde se conseguiu reproduzir as mesmas condições de condução (velocidade de $80 \mathrm{~km} / \mathrm{h}$ e rotação do motor em torno de 1450 rpm).

A figura 8 ilustra um trecho percorrido de velocidade constante, sem injeção de ARLA 32 (com o uso de "chip" emulador de ARLA 32), que compreende o intervalo de tempo do ensaio de pista de 5500s a 6500s. São apresentados os dados de: - concentração de NOx e CO2/100 em ppm; - Fluxo de Massa no Escape ; - temperatura de escape e velocidade do veículo em $\mathrm{km} / \mathrm{h}$ (velocidade GPS).

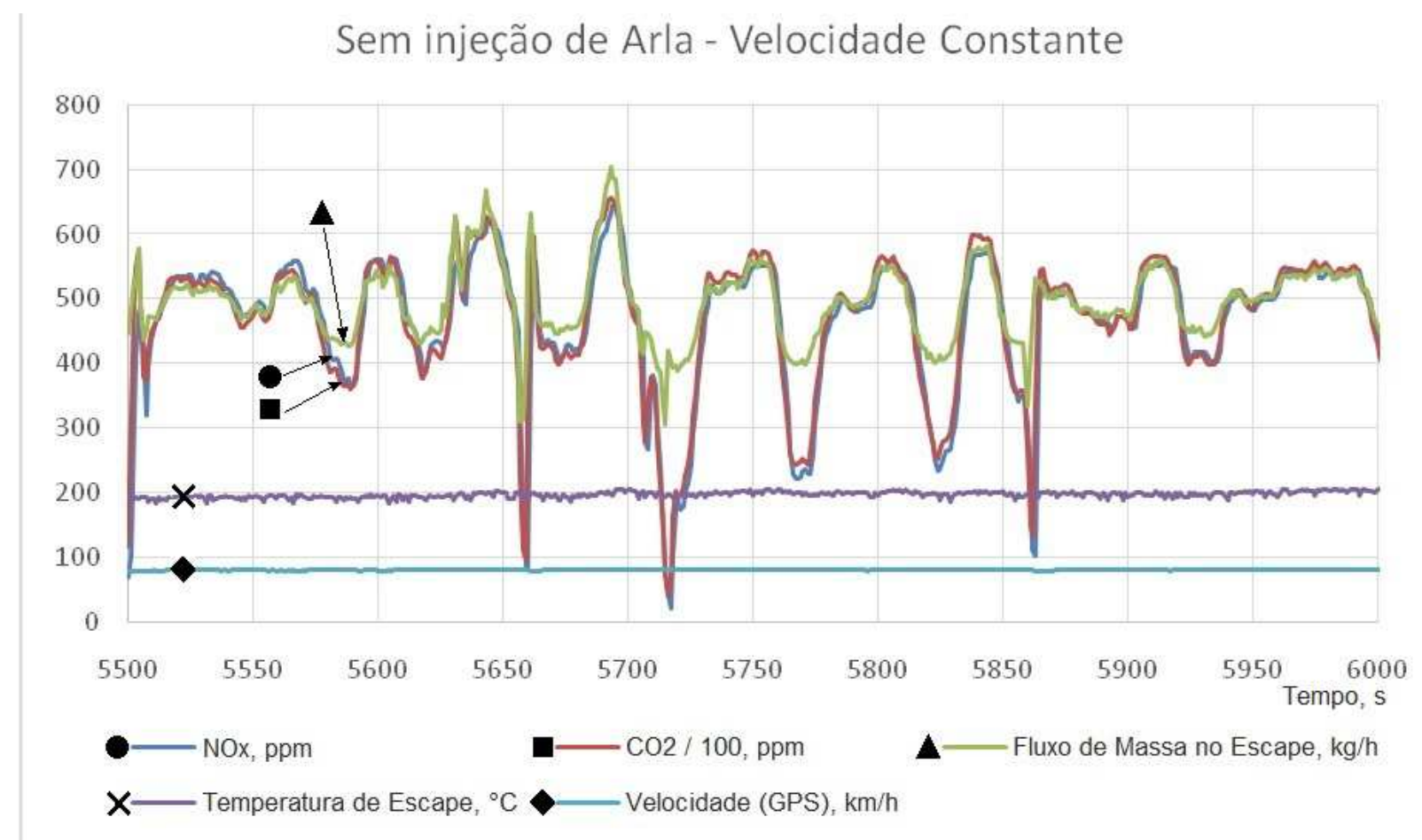

Figura 8 - Emissões de NOx do caminhão - SEM injeção de ARLA 32(emulador).

Para permitir a comparação das emissões de NOx com injeção de ARLA 32, foi elaborado um gráfico para o trecho com velocidade constante do caminhão em um intervalo de 450 segundos (figura 9). 


\section{Com injeção de Arla - Velocidade Constante}

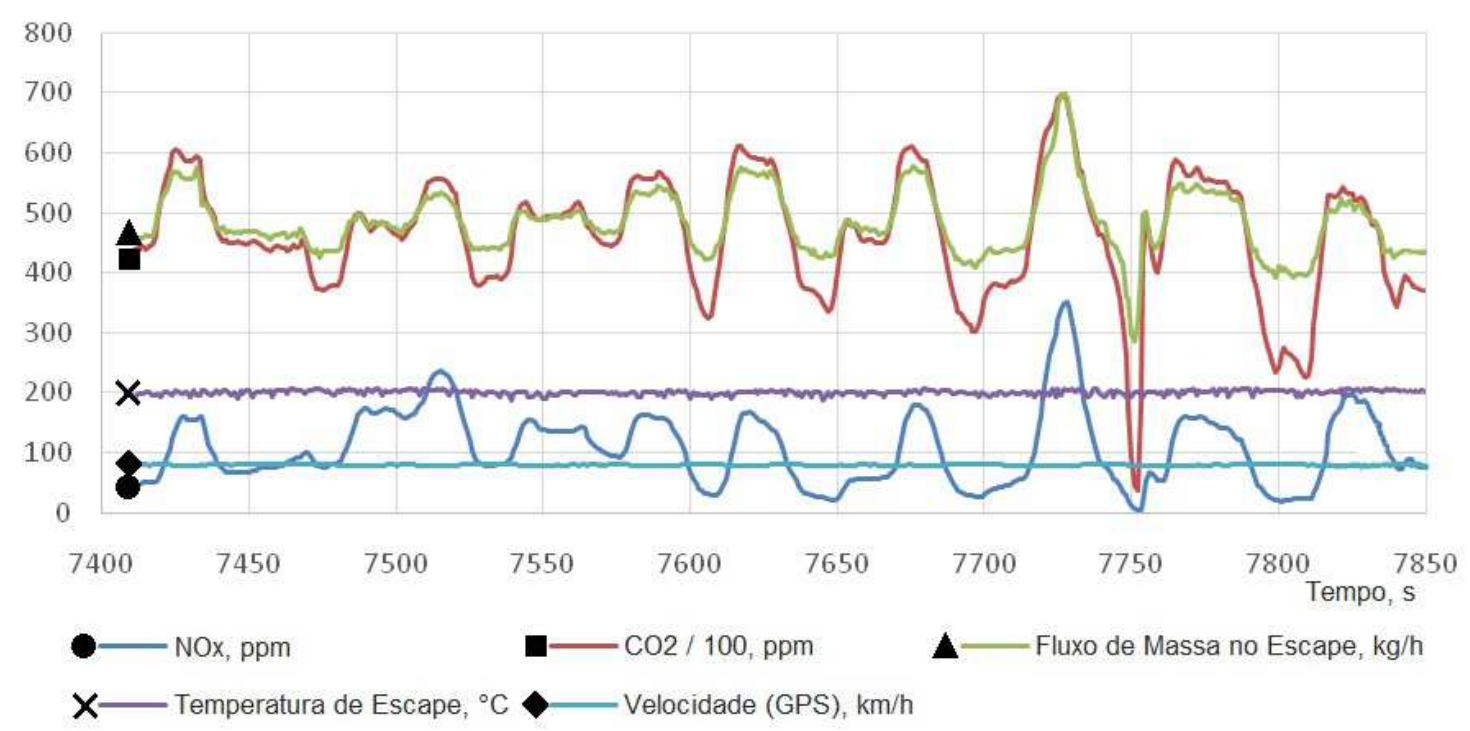

Figura 9 - Emissões de NOx do caminhão - COM injeção de ARLA.

Observa-se nas figuras 8 e 9 que a velocidade do veículo foi em torno de $80 \mathrm{~km} / \mathrm{h} \mathrm{com} \mathrm{modo}$ de condução automático e que há alguns picos e vales na medição de $\mathrm{CO} 2 / 100$. As variações da emissão de $\mathrm{CO} 2$ ocorreram em função da correção do piloto automático do veículo, devido a variações de vento e de variações da pista, entre outros fatores. Observa-se que os valores de fluxo de exaustão de gases e de NOx também acompanharam a variação do CO2. A temperatura dos gases de exaustão medida no equipamento "PEMS" ("on-board") ficou estável e em torno dos $200^{\circ} \mathrm{C}$ em ambos os casos, significando que o SCR estava aquecido.

Para realizar uma melhor comparação das duas medições, foram elaboradas as tabelas 5 e 6 , que mostram os resultados da média, do máximo, do mínimo e o desvio padrão (Desv. Pad.) das variáveis medidas nos ensaios de pista.

Tabela 5 - Resultados de emissões de NOx do caminhão - SEM injeção de ARLA 32.

\begin{tabular}{|l|c|c|c|c|c|}
\hline & Unidade & Média & Máximo & Mínimo & Desv. Pad. \\
\hline NOx & $\mathrm{ppm}$ & 466 & 644 & 22 & 106 \\
\hline CO2 / 100 & $\mathrm{ppm}$ & 470 & 657 & 39 & 104 \\
\hline Fluxo de Massa no Escape & $\mathrm{kg} / \mathrm{h}$ & 496,0 & 704,0 & 304,4 & 57,3 \\
\hline Temperatura de Escape & ${ }^{\circ} \mathrm{C}$ & 197 & 206 & 183 & 4,6 \\
\hline Velocidade (GPS) & $\mathrm{km} / \mathrm{h}$ & 79,9 & 81,2 & 78,2 & 0,5 \\
\hline
\end{tabular}

Tabela 6 - Resultados de emissões de NOx do caminhão - COM injeção de ARLA 32.

\begin{tabular}{|l|c|c|c|c|c|}
\hline & Unidade & Média & Máximo & Mínimo & Desv. Pad. \\
\hline NOx & $\mathrm{ppm}$ & 108 & 352 & 3 & 63 \\
\hline CO2/100 & $\mathrm{ppm}$ & 463 & 697 & 36 & 99 \\
\hline Fluxo de Massa no Escape & $\mathrm{kg} / \mathrm{h}$ & 484,6 & 698,5 & 285,8 & 54,6 \\
\hline Temperatura de Escape & ${ }^{\circ} \mathrm{C}$ & 201 & 208 & 188 & 4 \\
\hline Velocidade (GPS) & $\mathrm{km} / \mathrm{h}$ & 79,6 & 80,8 & 77,9 & 0,5 \\
\hline
\end{tabular}


Observando os dados das tabelas 5 e 6, pode ser verificado que, na média, a emissão de NOx SEM injeção de ARLA 32(466 ppm) ficou muito acima do valor de NOx COM injeção de ARLA 32(108 ppm). Apesar da velocidade do veículo ser estável e apresentar baixa dispersão (desv. Pad. igual a $0,5 \mathrm{~km} / \mathrm{h}$ ) a emissão de NOx ainda apresentava um desvio padrão elevado, provavelmente devido a pequenas inclinações da pista e a fatores ambientais diversos.

De forma a reduzir o desvio padrão das leituras dessa análise, foi escolhido para o teste sem injeção de ARLA 32 (com o emulador instalado), o trecho do trajeto de pista plana compreendido entre o intervalo de tempo 5515 e 5655s (intervalo de 140 s), e o trecho de pista plana equivalente para o período com injeção de ARLA 32, sendo o intervalo de tempo entre 7410 e 7700s (intervalo de 290 s). As figuras 10 e 11 e as tabelas 7 e 8 resumem os dados dos testes dos novos trechos escolhidos, incluindo NOx, CO2/100, Fluxo de Massa no Escape, temperatura de escape e velocidade do veículo em $\mathrm{km} / \mathrm{h}$ (velocidade GPS).

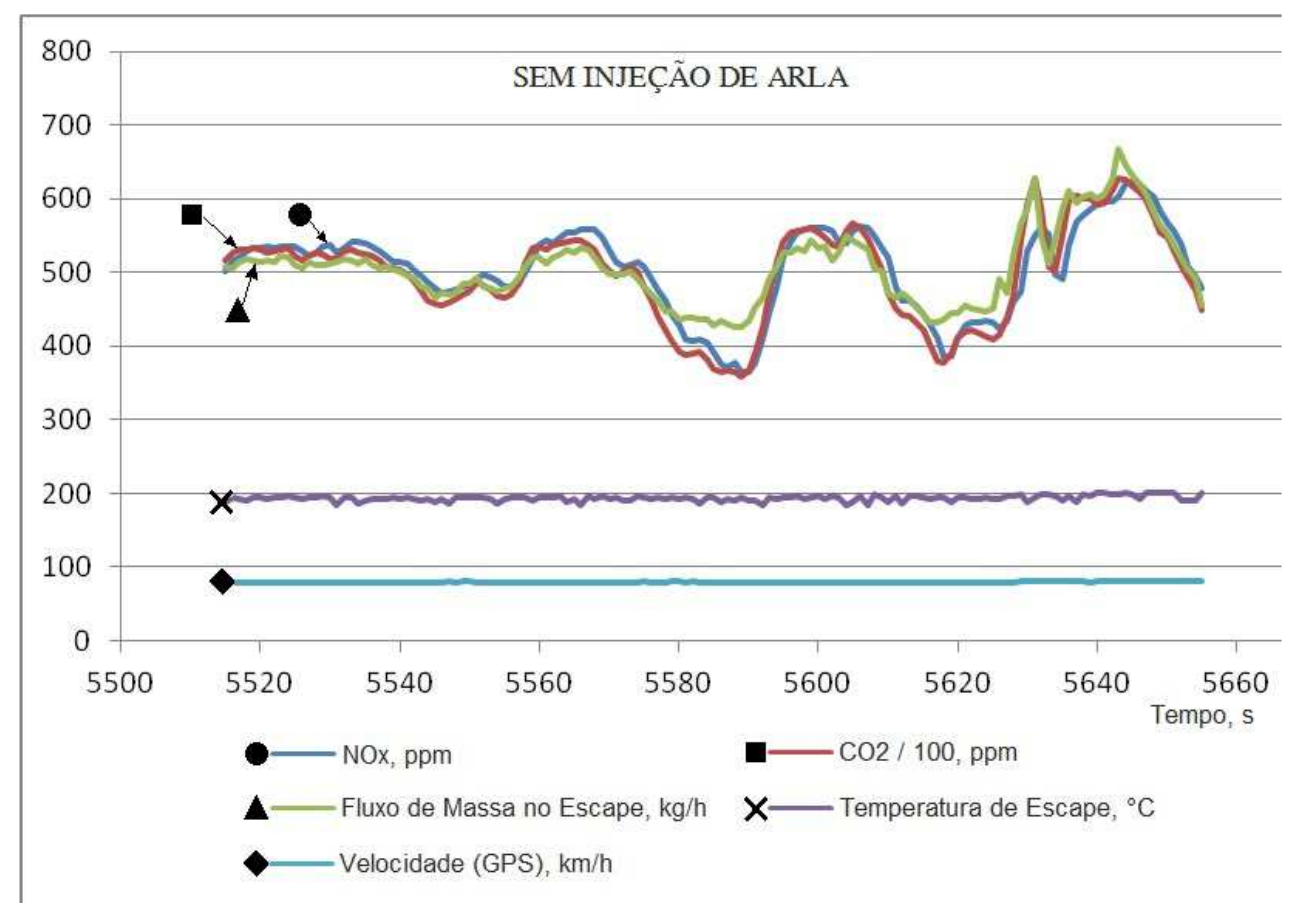

Figura 10 - Detalhe das Emissões de NOx do caminhão sem injeção de ARLA 32 


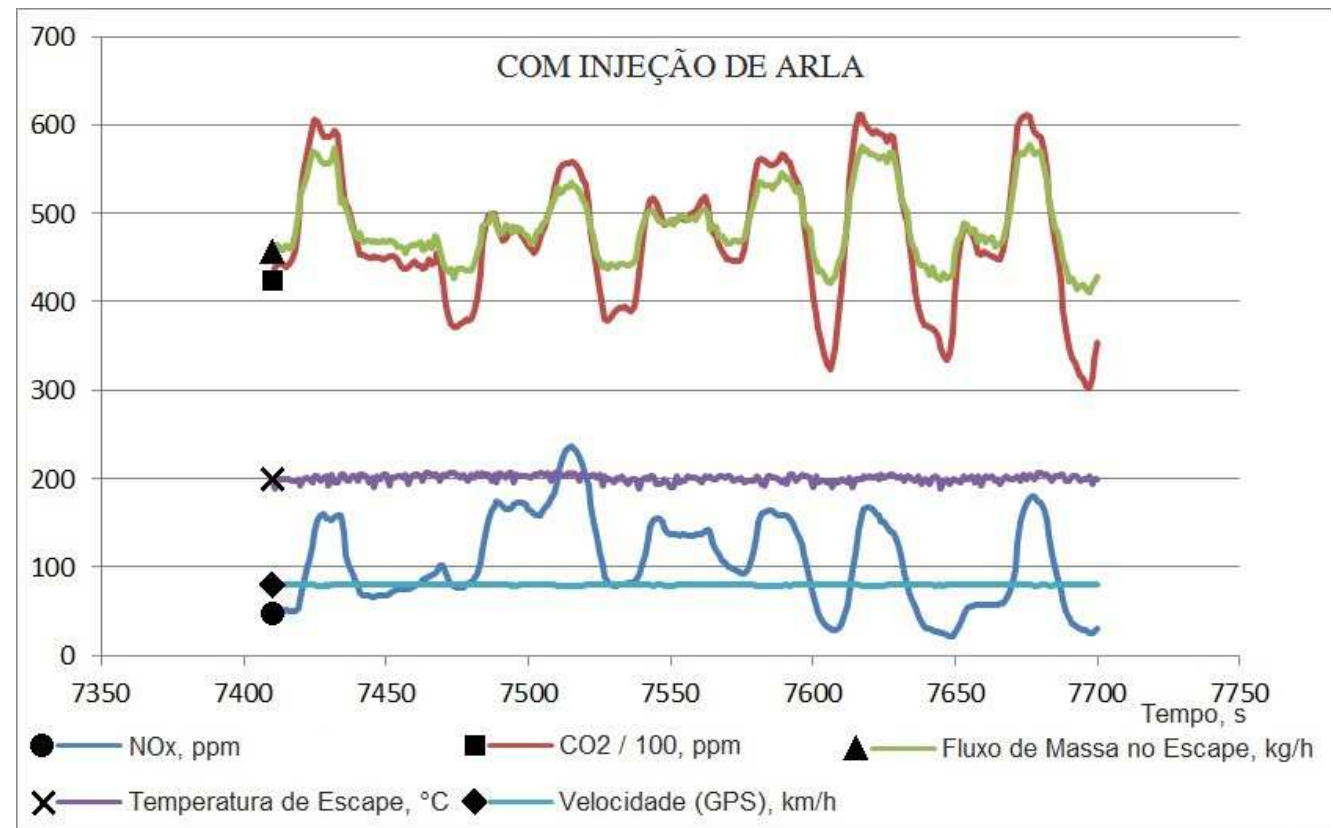

Figura 11- Detalhe das Emissões de NOx do caminhão com injeção de ARLA 32

Tabela 7 - Resultados de emissões de NOx SEM injeção de ARLA 32(trecho 5515 a 5655 s).

\begin{tabular}{|l|l|c|c|c|c|}
\hline & Unidade & Média & Máximo & Mínimo & Desv. pad. \\
\hline NOx & $\mathrm{ppm}$ & 505 & 623 & 365 & 60 \\
\hline CO2 / 100 & $\mathrm{ppm}$ & 498 & 628 & 359 & 66 \\
\hline Fluxo de Massa no Escape & $\mathrm{kg} / \mathrm{h}$ & 507 & 667 & 426 & 51 \\
\hline Temperatura de Escape & ${ }^{\circ} \mathrm{C}$ & 193,5 & 201,8 & 183,1 & 3,7 \\
\hline Velocidade (GPS) & $\mathrm{km} / \mathrm{h}$ & 79,7 & 80,9 & 78,9 & 0,4 \\
\hline
\end{tabular}

Tabela 4 - Resultados de emissões de NOx COM injeção de ARLA 32(trecho 7410 a 7700 s).

\begin{tabular}{|l|l|c|c|c|c|}
\hline & & Média & Máximo & Mínimo & Desv. pad. \\
\hline NOx & $\mathrm{ppm}$ & 107 & 236 & 21 & 52 \\
\hline CO2 / 100 & $\mathrm{ppm}$ & 473 & 612 & 302 & 75 \\
\hline Fluxo de Massa no Escape & $\mathrm{kg} / \mathrm{h}$ & 487 & 578 & 410 & 42 \\
\hline Temperatura de Escape & ${ }^{\circ} \mathrm{C}$ & 200,2 & 206,7 & 188,0 & 3,8 \\
\hline Velocidade (GPS) & $\mathrm{km} / \mathrm{h}$ & 79,6 & 80,7 & 78,5 & 0,4 \\
\hline
\end{tabular}

Com base nos dados das tabelas 7 e 8 pode ser verificado que as emissões de NOx aumentam 4,7 vezes com o uso do dispositivo emulador ("chip"). Pode ser verificado, também, que as emissões de $\mathrm{CO} 2$ para as duas situações foram próximas, ou seja, condição de carga equivalente para os dois ensaios (COM e SEM ARLA 32). Com base na vazão mássica do escapamento, da concentração em ppm de NOx e do valor da densidade desse poluente disponível na norma NBR 15634 foi feito o cálculo da emissão em g/km de NOx e de CO2 para os dois casos. Com o uso do emulador ("chip") os valores foram de $\mathrm{NOx}=5,2 \mathrm{~g} / \mathrm{km} \mathrm{e}$ $\mathrm{CO} 2=488 \mathrm{~g} / \mathrm{km}$ e para o veículo em condição original (com injeção de ARLA 32) os valores foram de $\mathrm{NOx}=1,1 \mathrm{~g} / \mathrm{km}$ e $\mathrm{CO} 2=446 \mathrm{~g} / \mathrm{km}$. Esse aumento das emissões de NOx com o uso do emulador ("chip") representa um grande impacto negativo na qualidade do ar e na saúde das pessoas segundo o trabalho de SZWARC [12]. 


\section{CONCLUSÃO}

Cinco formulações de ARLA 32 foram feitas, sendo uma referência especificada e outras quatro que simulavam possibilidades de adulteração. Duas formulações usaram ureia fertilizante, sendo uma diluída com água potável comum (FERT_AGC) e outra com água desmineralizada (FERT_AGD). Outra formulação foi feita a partir do ARLA 32especificado pela diluição adicional com $10 \%$ de água potável comum (ARLA_AGC). A última formulação usou ureia industrial e água desmineralizada (IND_AGD).

Considerando o ARLA 32 especificado como referência, nos ensaios de emissões de NOx em banco de provas foram verificados aumento da emissão de NOx de até 13\% para as formulações que usuram ureia fertilizante e ureia industrial. Com relação à formulação que usou adicional de $10 \%$ de água no ARLA 32 (ARLA_AGC), o aumento foi de até $32 \%$. Apesar do aumento de NOx com o uso das formulações adulteradas, todos os valores encontrados para o motor usado foram abaixo do limite de 2,0 g/kWh do PROCONVE, com exceção da formulação que usou água comum (ARLA_AGC), que teve o valor de 2,03g/kWh.

As emissões de NOx brutas do motor testado foram da ordem de 7,5 g/kWh. No caso do uso de um dispositivo eletrônico nesse motor, que iniba a injeção de ARLA 32, o valor das emissões de NOx do escapamento seriam iguais às emissões brutas e o motor teria níveis equivalentes a um motor da fase CONAMA P4 ou P3.

Com relação ao sistema de injeção de ARLA 32, ao final dos ensaios de emissões em banco de provas, de duração de cerca de 3 a 4 horas, as formulações ARLA_AGC e IND_AGD apresentaram elevada formação de depósitos no injetor de ureia. O uso prolongado dessas formulações pode gerar entupimento do injetor de ureia e danos ao sistema SCR.

Foram realizados ensaios de emissões de NOx em um caminhão 2014 com tecnologia da fase CONAMA P7, equipado com sistema SCR na sua configuração original e com o uso de "chip" que inibe a injeção de ARLA 32. Para a condição de teste de veículo em velocidade constante de $80 \mathrm{~km} / \mathrm{h}$, as emissões de NOx, com o uso de "chip" emulador de ARLA 32foram de 4,7 vezes superiores aos valores obtidos com o veículo em sua configuração original. Os valores encontrados mostram uma eficiência de conversão do sistema SCR da ordem de $80 \%$. Esse valor é próximo ao encontrado nos ensaios em banco de prova de motor realizados.

Os resultados desse trabalho podem contribuir em discussões que buscam a redução do uso inadequado do ARLA 32, evitando o aumento das emissões de NOx pelos veículos pesados. 


\section{REFERÊNCIAS BIBLIOGRÁFICAS}

[1] RESOLUÇÃO CONAMA n 403, de 11 de novembro de 2008. MINISTÉRIO DO MEIO AMBIENTE - CONSELHO NACIONAL DO MEIO AMBIENTE - CONAMA. Publicada no DOU n 220, de 12 de novembro de 2008, Seção 1, página 92.

[2] SCHULTE, D. , Atualização sobre o mercado de ARLA 32, 4th INTEGER EMISSIONS SUMMIT BRAZIL, INTEGER, maio de 2014, SP.

[3] GAYNOR, P., REID, B., HARGRAVE G., LOCKYER T., WILSON J., An Experimental Investigation into DEF Dosing Strategies for Heavy Duty Vehicle Applications, SAE 201501-1028.

[4] STOLA F., DE CESARE M., LACCHINI L., CAVINA N., JOUR S. S., Diesel Exhaust Fluid ( DEF ) Supply System Modelling for Control and Diagnosis Applications, SAE 201526-0090.

[5] ZHENG G., FILA A., KOTRBA A., FLOYD R., Investigation of Urea Deposits in Urea SCR Systems for Medium and Heavy Duty Trucks, SAE 2010-01-1941.

[6] MILPIED J., FROBERT A., LEPREUX O., Sensitivity of SCR Control Strategies to Diesel Exhaust Fluid Quality : A Simulation Study, SAE 2015-01-1051.

[7] KADU S., GANGWAR H., Urea Quality Sensor Integration in Urea Supply Line / Urea Tank, SAE 2012-01-1086.

[8] ABNT NBR ISO 22241-1: 2011 - Motores Diesel - Agente Redutor Líquido Automotivo - ARLA 32. Parte 1 - Requisitos de qualidade 2011, ABNT.

[9] SIMÃO, V. , Programa de Avaliação da conformidade do ARLA 32, 4th INTEGER EMISSIONS SUMMIT BRAZIL, INTEGER, maio de 2014, SP.

[10] LEAL, G., Seminário ARLA 32 e Seu Papel no Controle da Poluição do Ar, AEA Associação Brasileira de Engenharia Automotiva, SP, 11/08/2009.

[11] NBR 15634 - Veículos rodoviários automotores - Análise e determinação do gás de exaustão segundo os ciclos ETC, ESC e ELR, Segunda Edição - Norma Técnica Brasileira ABNT, 13/08/2012.

[12] SZWARC, A., Impacto ambiental da não utilização do ARLA 32 em caminhões, 4th INTEGER EMISSIONS SUMMIT BRAZIL, INTEGER, maio de 2014, SP.

Para esclarecimentos adicionais, contatar:

Tadeu Cavalcante Cordeiro de Melo, email: tcm@ petrobras.com.br

PETROBRAS/CENPES. Tel: 2121626724 